\title{
Implementability of Benchmarking (Comparative) Technique in Sports Enterprises (Sample Elazig)
}

\author{
Oguzhan Altungul ${ }^{1}$, Reşat Demirag ${ }^{1}$ \\ ${ }^{1}$ Firat University, Turkey \\ Correspondence: OguzhanAltungul, Firat University, Turkey.
}

Received: August 2, 2017

Accepted: August 22, 2017

Online Published: August 27, 2017

doi:10.11114/jets.v5i9.2624

URL: https://doi.org/10.11114/jets.v5i9.2624

\begin{abstract}
Increasing competition in domestic and foreign markets in the globalizing world and increasing quality expectations of customers have led enterprises to develop and implement a range of different quality considerations in order to remain competitive or to increase competitive power. One of the most important of these approaches is called benchmarking in the international literature, which is called "the best of the best" in businesses.
\end{abstract}

The purpose of this study was to evaluate the Benchmarking approach of management and science concepts of sports enterprises operating in Elazig.

The universe of the research is the sports enterprises in Turkey and the sample is the sports enterprises in Elazig province. The research was evaluated as collecting and analyzing benchmarking information.

In the qualitative survey, sports and social facilities benchmarking services, financial data collection tool and sports facility participants questionnaire were applied. The questionnaire developed by Peter Taylor was translated into Turkish and validated and credible, and Cronbach alpha value $\alpha=0,816$.

A significant difference was observed when participants' participation in sports facilities in Elazıg was examined in terms of place of birth according to the AnovaTukey test.

As a result; Although there was a significant difference between the expectations of the participants coming to sports facilities operating in Elazıg province $(p<0,05)$, there was no significant difference between their satisfaction $(p>$ $0,05)$.

Compared to the sports facilities in Elazig, it can be considered that there are many deficiencies in all sports facilities and that no professional management is used.

Keywords: manager, sport facilities, benchmarking

\section{Introduction}

In today's world of information and communication, which has come to a great market position, "change" emerges as a basic element of development in a sense. Businesses depend on their ability to survive, their structures, their products, their processes and the markets in which they operate. Organizations have to reorganize their structures, respond faster to the market, focus on customer wants and expectations, innovate, be flexible and control this rapid change (Hasan \& Thomas, 2000). As a result, it can be said that the success of enterprises in today's competitive environment depends on their adaptation to ever-changing environmental conditions. In other words, in an environment of increasing global competition, the point that is generally emphasized is to decide what constitutes the "best" organizational structure among the limiting factors that limit the existing conditions and organization (Cristobal, Angel \& Jose, 2003.).

Increasing competition in domestic and foreign markets in the globalizing world and increasing quality expectations of customers have prompted businesses to develop and implement a range of different quality considerations in order to remain competitive or to increase competitive power (Jaffar, Mohamed \&Yasar, 2000). One of the most important of these approaches is "benchmarking" which in the international literature is called the best in businesses. Benchmarking theory which is one of the concepts of management will be evaluated in terms of sport management and organizations in this study. 


\subsection{Sport Facilities Concept}

The concept of sport has also been influenced by this change and new sub-domains within sport management have begun to emerge (Argan, Katırc1, 2008).

According to Güclü (1998); Sports facility is used to describe all kinds of sport activities (hall, stadium, track etc.). It is also possible to think of such concepts as forests, forests, rivers, canyons, which allow various sports activities to be carried out. Sports facilities are sports areas that offer active and / or passive participation opportunities by public and private organizations.

Sports facilities established by real or legal persons in Turkey operate in accordance with the Regulation on Private Physical Education and Sports Facilities. Article 4 of the Regulation defines sports facilities as "Places opened by real or legal persons for physical education and sports activities". According to Article 9 of the Regulation, sports facilities must have the following qualifications:

- At least two dressing rooms, at least one dressing room, at least two dressing rooms for female and male athletes, at least two dressing rooms, no lockers or hangers for the athletes, a lighting and ventilation system for the rooms, $\mathrm{C}$, and hygienic conditions,

- Use of at least one resting area that is not less than $15 \mathrm{~m}^{2}$ in area of use, covering of the rest room floor with carpet floor, parquet and similar materials, lighting of the room, lighting and ventilation should be sufficient,

- At least two showers and two toilets in the locker rooms in facilities where ladies and gentlemen sports together,

- The presence of hot water in showers,

- The temperature of the spot work is not lower than $18^{\circ} \mathrm{C}$, the work area is at a sufficient level according to the number of athletes,

- The fact that the plant floor is covered with wood, parquet, chipboard, carpet and similar materials according to the characteristics of the sports branches, the ground according to the characteristics of sports branches made in open facilities; To be covered with grass, asphalt, concrete and similar materials foreseen by the relevant federations,

- Fire extinguishing and similar equipment ready for fire and natural disasters (Powerful, 1998).

In order to provide physical preventive measures during the operation, sharp edges of sharp edges which are dangerous in the work area are covered with lightening soft materials and the absence of pillars, columns, trenches, pits, soil piles, trees and similar obstacles,

- Keeping sporting equipment and auxiliary equipment to be sufficient for the number of athletes in the working group,

- All units of the facility where special physical education and sports activities are to be conducted should not carry contrary conditions to general health,

- Any precautions have to be taken in order to avoid disturbance of the surroundings due to noise, pollution etc. during the activity to be carried out at the special sports facility (Powerful, 1998).

\subsection{Sport Facility Management Concept}

In a broad approach, the enterprise can be defined as "an organization that operates to produce and / or market economic goods and services by bringing production factors together in a harmonious way to meet the needs of people". In a narrow sense, the enterprise is "the economic unit that operates to produce goods and services to meet the needs of others and to make profits" (Simsek, 2008).

Sports facility enterprises are service enterprises and they are the units that produce sports service by organizing the production factors in a planned way in order to meet the sportive needs of the individuals. We can refer to sports facility enterprises in general as "a social, economic and technical unit that allows the implementation of sporting activities, brings together production factors for social benefit and / or profit, and produces sports service".

\subsection{Purposes of Sports Facility Enterprises}

Profit cannot be the general aim of commercial enterprises, but profit of the establishment and operation of sports facilities. It has a lot of advantages compared to sports facilities. These aims can be addressed in the following way (Serarslan, 2006).

Achieving Profit: One of the main objectives of private sports facility enterprises and commercial partnerships is to make profits. In private sports facilities, profit is an important measure for both guiding decisions and evaluating the results.

Providing Social Benefit (Yield): In countries such as Turkey where sports are generally promoted by the state, most of 
the sports facilities belong to the public sector. The main objective of publicly owned sports facility enterprises is to provide social benefits by producing equal, effective and efficient services. The first and the main purpose in these facilities is to create social service and social benefit by spreading sports. Dissemination of sport: Sport in Turkey is considered as state policy (Fisek, 2003). Article 59 of the Constitution of the Republic of Turkey states that "the State shall take measures to improve the physical and mental health of the Turkish citizens of all ages, encouraging the spread of the sport to the masses ...". In this context; one of the most important aims of our country, especially public sports facilities, is to contribute to the widespread use of sports within the society. Promoting Sports Brands: Promoting sports such as promoting sports and running traditional sports such as javelin and oil wrestling are also among the major goals of publicly owned sports facility operators. Creating Consumer Satisfaction: Today, we can see that many different types of services are provided in sports facilities, from catering services to entertainment services prepared for children. The main purpose here is to create consumer satisfaction by increasing perceived quality of service.

Implementing Social Responsibilities: Sports facility management is responsible for improving the quality of life of the communities in which they operate, establishing sustainable and quality communication with the community, and supporting economic, environmental, cultural and social development. Upgrading the Image of the Enterprise in Its Context: This goal is mainly aimed at the enterprises of the sports facility enterprises. The corporation provides service according to the purpose of the enterprise which is in the sports facilities.

\subsection{What Is Benchmarking?}

The concept of quality has been an important concept throughout history. People are willing to pay more for a quality product or service. In contemporary sense, the concept of quality has reached the theoretical basis with Deming.

W. Edwards Deming has had a major share in the work of creating Japanese goods in the aftermath of 1950 in the image of being the best quality merchandise in the world (Argüden, Unanoglu, 2009)

Benchmarking is the process of learning how to work in business life, measuring it continuously, making it comparable to other institutions, and seeing and improving the development areas of our own operation.

There are 4 main elements in the concept of "comparison".

Measuring: Measuring the performance levels and developments of ourselves and the partners to be "benchmarked".

Benchmarking: To compare activities, applications, performance.

Learning: Implementing the learning process by determining the causes of differences in the result of comparison.

Development: To set up a business plan in the form of learning outcomes determined in steps, and to determine improvement by implementing it.

As a result of benchmarking, good progress can be achieved with proven applications.

- Benchmarking gives you a better understanding and improvement of business processes.

- Process errors of best cases are 500-1000 times lower than industry averages.

-It is 2-3 times faster than the average product development time of the leading producers.

- Ensures appropriate and reachable targets.

- Improve the accuracy of the measurement of productivity.

- Capable of examining the strategies of collaborating partners, better interpreting the course of the market, and reacting more easily to possible changes.

- Benchmarking programs determine who has a stronger quality approach than the partners.

- Benchmarking forces the restructuring of institutions.

As a result of benchmarking, the institutions that make the necessary structure show much faster progress.

- Problem solving enhances the efficiency of teamwork. At the same time, the acquisition of the habit of analyzing tangible gains increases the quality of the decisions taken in the institution.

- Benchmarking encourages learning and motivates development (Argüden, Unanoglu, 2009).

\subsection{Types of Benchmarking}

Benchmarking studies are divided into internal benchmarking and external benchmarking. The types of benchmarking in the book are examined in six branches (Bektas, 2001).

Institutional Benchmarking:

The in-house comparison method provides your definition of our institution. The simplest and least expensive type of 
comparison. Activities between departments are compared with each other.

In-house comparison is also the type of benchmark in which the institution has the lowest risk of failure to implement because it examines its own activities. However, if departments think that competition is created within them, the most difficult Benchmarking can be. It is not learning the different parts, but learning. The question to be asked is "Who is involved with this subject?" (Golgsmith, 2008).

In order to make benchmarking within the organization, the flow diagram can be used (Peter \& Diane 2007) Are there similar internal processes?

1

3

Do they have the same inner
processes?

Yes

Do benchmarks exist?

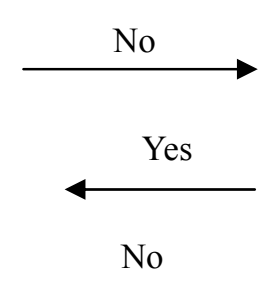

5

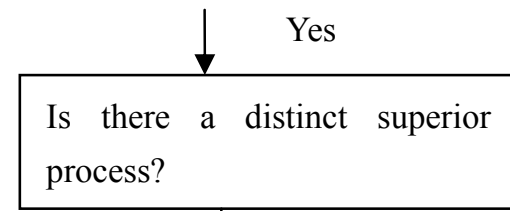

6

Can applications be transferred?

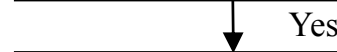

8

Do an internal coarse search
No

2

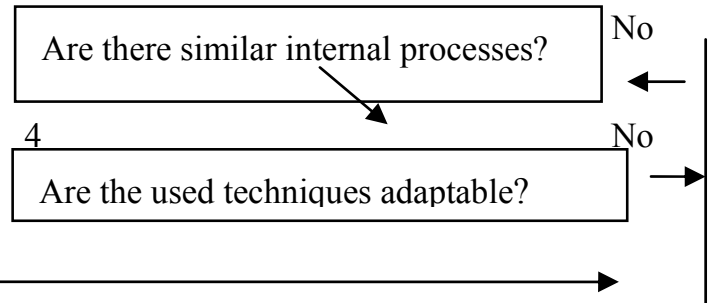

No

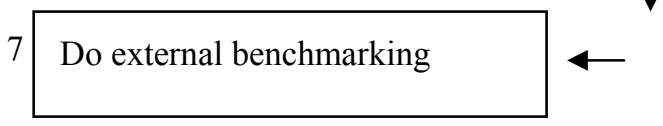

Figure 1. Intra-site benchmarking method

The first step in the flow diagram in Figure 1 is to question whether the same processes exist in the institution. As an example, we can look at two factories that produce the same product installed in different cities. In this case the third step is passed. If there are no similar processes, the second step is questioned whether there are similar processes. If there is no similarity in the internal processes, research should be done to make an external Benchmark. If similar internal processes exist, their adaptation should be examined to see if they are appropriate. In general, adaptation techniques in production are the responsibilities of process or quality engineers (Argüden, Unanoglu, 2009).

Rival Benchmarking:

Because of the trade secrets of the institution, it is necessary to make a rival business association. Raki's data may be obtained from public information sources, sales organization or suppliers. In general, the competitive comparison study covers a period of six to twelve months and is the easiest type of comparison after internal comparison, since similar processes are compared with competitors.

The benefit of comparing the rival is that it allows us to look at our own activities from the outside. Buying is better than the internal comparison with the results, and it is easier to adapt the information to the institution with the advantages of being in the same sector. Adapting is the use of available information, taking into account the internal dynamics of our own operation, once we understand the present situation (Anatoliy, 2008).

Batch Benchmarking:

An alternative to Ratio Comparison is that information exchange is somewhat more limited and that the consortium formed by several institutions compares collectively. Batch Benchmarking takes less than six to twelve months and is less costly than comparative Benchmarking.

Batch Benchmarking generally focuses on statistical methods. It is the reason for preference to give a general idea of making complex comparisons (Argüden, Unanoglu, 2009).

Hidden Benchmarking: 
It is called "Hidden benchmarking" to be subject to comparison without being aware of the rival. It lasts 6-12 months and is more costly than the comparative Benchmarking method. Hidden Compare highest yield is obtained when comparing the common processes to each other.

It is easier to make Confidential Benchmarking to top management. It does not depend on one because it does not need a real partner, but it is difficult to control whether the future data are incomplete or incorrect. These studies help to better direct resources, prevent investment mistakes, and prepare to grow in the market without feeling competitors (Argüden, Unanoglu, 2009).

The Definition and Priority of Benchmarking Concept:

The concept which has not yet been adopted in Turkish and accepted as a common consensus but tried to be translated into Turkish in the form of sampling and comparison; Cannot be fully met by words, it leads to misunderstandings (Fisek, 1980).

The term "benchmark" is used in Turkish dictionaries to refer to fixed points, references, signs used to remember a measure later, signs of the people who work on a rock, a wall, or a building. Benchmarking in a managerial sense is a management technique or a managerial tool (Öztürk, 2010).

The comparative definitions in the management literature are included (Victor, 2002);

Benchmarking, by identifying the "best practice" within an organization itself or other organizations to improve its performance level; Adapt to its own organization. Benchmarking, not benchmarking, comparing with other organizations; to find the best practices and adapt them to their own structure.

Benchmarking with approaches to human behavior; Accepting that others may be good; Is to be able to access the learning discipline and adapt it to itself without imitation.

$>$ The purpose of benchmarking; Is an uninterrupted learning process that enhances performance.

$>$ Benchmarking; Researching, finding, learning and adapting to the best or the better of the processes that are prioritized by the organization; It is the process of ensuring continuous improvement.

$>$ Continuous evaluation of products, services and processes against famous and strongest competitors in the field.

$>$ Benchmarking; The braid goes out of its shell. To deal with the events in the organization constantly, to learn indirectly the changes in the environment, to see one self perfect, to believe that there is nothing to be learned from other organizations; The development of organizations is a limiting factor. Benchmarking understands changes outside the organization; It treats them as a scientific process to interpret their organization.

$>$ Benchmarking; An important member of the learning organization understanding is a learning and teaching, understanding and adaptation, sharing and development process.

$>$ In the definitions, we can list the "common points" about benchmarking as follows:

$>$ Continuous improvement process,

$>$ To learn from others,

$>$ to adapt learning to their own organization,

$>$ To take measures to meet customer expectations and expectations and to provide future expectations,

$>$ Provide market leadership and lasting competitive advantage.

$>$ benchmarks; Copying, industrial espionage, sightseeing trips to other organizations. At the same time, it is an approach beyond market research activities and competitive analyzes; Nor is it a cheap tool that can be implemented in a short time.

\subsection{Development of Benchmarking in Turkey}

In our country, in order to gain the importance of globalization, to enter international markets, to increase competitive power, to produce quality goods and services; It has begun to be used as a new management technique (Pınar, 1996).

Within the framework of the restructuring works in the Eczacibası Group in 1995; The first benchmarking studies were implemented in marketing and sales functions and a team was set up to carry out the studies (Pınar, 1996).

Bench marking's Importance:

Using a benchmarking technique is important for a business because of the following reasons (Kaya, 1997, Fisher, 1998):

- The operator determines the difference between competing firms. 
- Allows a product or service to compare quickly and effectively within market conditions.

- It provides information on many sectors, helps to identify quality standards and to see the company's objectives in the industry.

- It is possible to examine the processes that have been successful in the enterprises and organizations throughout the world, and to be able to provide opportunities.

R. Camp also focuses more on the performance it emphasizes.

- Benchmarking compares the areas in which others are good, the administrative structure of the designated business, and the activities it is implementing, to reveal the development the business is aiming for.

- Effort and time spent by repeating the previously found methods and techniques are prevented.

- Determine at what points the change should be made and what kind of results are desired to be achieved after the change.

If Benchmarking is to be distinguished from a result-oriented approach and to be explained with a process-oriented approach, the benefits provided by this technique-based management approach and therefore the importance can be better understood. The differences between the results-oriented classical approach and the process-oriented benchmarking are shown in Table 1 (Aktan, 1999).

Process-focused Benchmarking difference with Results-Focused Classical Understanding

\begin{tabular}{ll}
\hline Result oriented & Process Focused \\
\hline Look at the results, & the process, \\
The process controls, & How it's done, \\
Make in-house comparisons, & Comparison with other institutions \\
Unpublished research is conducted, & Research for mutual profit, \\
It is competitive, & Competition may not be, \\
Conducted confidentially, & Sharing is essential, \\
Works independently from each other, & It works with understanding of partnership, \\
There are habit of checking out riffles, & Cooperation is based on mutual agreement, \\
The aim is institutional knowledge, & Target-process knowledge \\
Focusing on institutional needs is essential, & Focus on customer needs is essential \\
\hline
\end{tabular}

\section{Features and Principles of Benchmarking}

Features that form the basis of benchmarking (Sarac, 2005):

$>$ Requires knowing their superiority,

$>$ Focus on leadership position,

Based on mutual and mutual benefit,

$>$ The basic principles are reasonably measurable,

$>$ Goal to progress requires commitment and discipline,

$>$ Active and continuous change and development orientation is essential,

$>$ A progressive and positive approach,

$>$ The most valid evidence for change,

$>$ Thoughts are evident,

$>$ Turning to best practices,

$>$ Based on top management support, 
The differences between the result-oriented classical approach and the process-oriented benchmarking are (Pinar, 1996):

Result-focused, benchmarking-based comparison

\begin{tabular}{|c|c|}
\hline Result oriented & Benchmarking Based \\
\hline - Look at the results, & - Look at processes, \\
\hline - Controls what happens, & - Controls how jobs are done, \\
\hline - Compares within the institution, & - Make comparisons with other institutions, \\
\hline - conducts research without sharing, & - conduct research for mutual benefit, \\
\hline - it is competitive, & - It may not be competitive, \\
\hline - Sustain privacy, & - Sharing is essential, \\
\hline - Works separately, & - Works with understanding of partnership, \\
\hline - The Independent, & - Cooperation is based on mutual agreement, \\
\hline - Checking, & - Have the habit of attaining development goals, \\
\hline - The aim is institutional knowledge, & - Target process knowledge, \\
\hline - Focusing on institutional needs is essential, & - Focus on customer needs is essential, \\
\hline
\end{tabular}

Benchmarking has its limits. Getting useful information from institutions and comparing services can make the output more difficult than comparable. While seeking best practices for Benchmarking for continuous improvement; there are some basic principles that must be adhered to in order to facilitate professional co-operation, to ensure efficiency and to maintain the ethical level:

1. Change principle: The information system means that the applicant is willing to give similar information at the same level of detail.

2. Privacy policy: exchange of information for benchmarking, for interested parties and institutions. This information should not be transferred to third parties without the consent and consent of the parties.

3. Principle of use: Information obtained as a result of cooperation for benchmarking should only be used for improvement and improvement in the own institutions' own business. Name of a participant; the use or announcement of data or practices related to it is subject to the permission of the participant.

4. First contact principle: The first contact of organizations with other organizations within the scope of possibilities shall be made by a person designated for Benchmarking.

5. Third Party Policy: When requested to provide information on third parties; Institutional name can be given.

6. Preparatory Principle: The parties involved in the benchmarking study; They should make appropriate preparations before the first meeting to demonstrate their beliefs in the benchmarking process and the contributions to the efficiency and effectiveness of the participants (Metin, 1995);

$>$ Pioneers in the sector,

$>$ Competitors,

$>$ Companies outside the industry,

$>$ Opponents who have not attained competitiveness but are capable of creating threats in the future,

$>$ Other entities of the group to which the operator belongs,

Suppliers group

Benchmarking Aims and Benefits:

We can express the aims of benchmarking in the following way (Daytime, 1995);

$>$ To increase organizational performance,

$>$ To increase competitiveness,

$>$ To increase customer satisfaction,

$>$ To get new ideas,

$>$ To ensure continuous development,

$>$ To help identify the objectives and objectives of the business, 
$>$ To define businesses that may or may not be competitors,

Your process or application; Compare the target company with the "good" process or applications and determine the difference,

$>$ To set high standards,

$>$ To change or strengthen the institution's culture,

$>$ To ensure that the institution is managed strategically,

$>$ Reducing costly,

$>$ Motivate employees,

Benchmarking is essential for continuous improvement and always better performance. The comparisons of non-benchmarked and applied benchmarks are given below (Tanju, 1997).

Benchmarking in sport and its applications:

Although comparing is traditionally used in the business world, it is also used in sports center management and is a useful way of analyzing its own standard in sport. You can use this process in several different ways; Either in the standard you set yourself up for, or in the standard set by the person you expect to compete (model, quality, setting) or in a standard you expect to achieve. As an example of this, we can take an athlete with a speed of 100 meters. It can aim to do the best that the individual can do to finish his opponent's time or to finish at the appointed time together with the time set in the race. These assessments will be different for each individual athlete and will target the goal that the individual wants to develop depending on the direction of performance. For some people, this can be looked at as an athlete, considering the person's previous experiences and how they are affecting them (Kaya, 1997).

Benchmarking in terms of Sports Organization (Benchmarking):

It is a strategic tool used by many organizations. Luffman and Kenny (1996) emphasize how benchmarking is important for an organization in the first place to compare oneself and others. These authors explain this. Comparison; The creation of an ongoing process of measuring an organization's products and services, procedures and processes involves opposition to successful contenders and leading companies in other industries. By contrast, businesses can discover the best practice method and how to implement it. In other words; for many sport organizations, comparison is a simple process. For each encounter there is a simple and precise measuring instrument: the scoreboard is also needed for other units of measurement (Aktan, 1999). Therefore, organizations, sports authorities; Often send technical and administrative staff, systems, structures, programs and innovations to other countries for comparison. For example, in the following examples, performance athletes may possibly be able to make use of Benchmarking techniques (Barker, Saipe, Sutton, Tucker, 2003).

Golf: To watch the video of an elite golfer and to analyze the elite athlete's turn to improve himself.

Swimming: Finding a training program for a committed and successful swimmer and finding out how many hours he has trained and comparing himself (Barker, et. al, 2003).

An example can be given for football coaches by setting out on the definition of Sporde Benchmarking. Benchmarking, a person learns best in an organization what the people in the business do, and usually takes a model of what they are doing (25). Goldsmith explained this definition with an example. In professional soccer laws, coaches sometimes visit other successful programs, learn and test what they do and how they succeed, and even follow and apply what is happening in other countries. Thus, organizations and sports authorities often send people to other countries to compare systems, structures, programs and innovations (Golgsmith, 2008).

In a study conducted by Sunay (2005) in the context of sport, management and education (Sunay, 2005) comparing the programs that produced "sports manager" in Turkey and in the world;

1. The number of the courses and the total number of courses in the program vary according to the universities.

2. Sports management group lessons almost all of the programs that produced " sports manager " in Turkey and in the world; is high in terms of number of courses and course hours.

3. In the course types studied in the programs examined, some changes have been found in the course hours of theoretical and applied courses. For example; The X practice course is taught in a university for 1 hour theoretical 2 hours, while in another university it is practiced for 4 hours.

4. In the sport management programs of the universities surveyed in Turkey, the course groups that should be included in NASPE and NASSM sports manager programs were observed (Sunay, 2005).

Benchmarking also provides a way for a strong, weak, and better understanding of an organization. Therefore, for 
strategic planning, the benchmarking is a useful tool in previous research; professional sports showed that developments resulted in a wide participation in sports events. As an example; in 2000, the Washington Capitals of the National Hockey League won the 2nd Southeast Division. To compare the benchmarking results of the Washington ice hockey club's 2000-2001 season results a year ago, the spectral success (Nourayi, 2007);

- $7.3 \%$ audience increase

- $50 \%$ TV coverage and revenue growth

- Increase in sponsor revenue

- Audience Revenue Growth (more than 15,000 per game)

Sales growth in the form etc.Team relations. Winning and losing records are used to predict attendance in such leagues, and it is believed that the success of the team and the increase in participation will also help to use the benchmarking management on the teams and show how far the teams are progressing and increase their gains (Nourayi).

A Study of the IFA (Irish Football Association):

A " Benchmarking System " was established in Northern Ireland's Department of Clubs. The following criteria were taken into account (29);

- Sportive Criteria

- Infrastructure Criteria

- Staff and Management Criteria

- Legal Criteria

With this system, the IFA's FIFA and UEFA rules are intended to be tailored to the statutory design rules. For this purpose, they employed recruitment staff to manage the licensing plans that would help the clubs during the licensing process, and the IFA member clubs interacted with each other. There has been a work to improve the whole process of the clubs' licensing applications and obtaining licenses (Ifa, 2006).

\section{Method}

In our country and in Elazig sports activities are held in private and public sports facilities. It was made to understand how much the sport facilities were enjoyed by the users and whether their expectations were met. Elazig activities and sports facilities ongoing use of expectations and satisfaction of the satisfaction of the people is not met if it is done to determine what is missing.

A survey study was conducted on 200 people using 18 sports facilities in Elazıg. In comparison between the facilities, 12 sports facilities constitute the sampling group.

The survey was conducted by Sheffield Hallam University (Sport Industry Research Center) Center for Sports Industry Research and Professor Dr. Peter Taylor, "Measuring the Performance of Sport Facilities" (Bektas, 2001) and "Sport Equity; The "Native Bencarming Service for Sports and Leisure Centers: Benchmarking Services for Sports and Social Facilities: Financial Questionnaire" (P1nar, 1996), which is included in the named activities of the Bencommmarking the performance of the public Sport Facilities, A 20-question questionnaire was developed by the National Benchmarking Service "Sport England Survey of Sports Facilitated Users".

When using the sports facilities of the people, it is in the form of 25 scale likert in terms of expectations and satisfaction.

"Very satisfied" 4.21-5.00 (5),

"Medium satisfied" 3,41-4,20 (4),

"What is not satisfied and pleased" 2,61-3,40 (3),

"Not satisfied with the medium" 1,81-2,60 (2),

"Very dissatisfied 1,00-1,80 (1)

It is rated on the basis of equal averages.

In the questionnaire, questions about the administrative and infrastructure of sports facilities were managed. In these questions, it was tried to determine the shortcomings of sports facilities. Errors and deficiencies identified in the questionnaire form have been eliminated by preliminary studies. In the validity-reliability analysis (Cronbach's Alpha), $\alpha=0.816$. As a result of applying the questionnaire, the data obtained were analyzed using the SPSS 21.0 statistical program. The frequency and percentages of the responses to the questions regarding demographic information and 
sports club managers' educational status and competences in the questionnaire were analyzed and the distributions were given in tabular form. The data obtained from the questionnaire were presented in tabular form with frequency, percentage, arithmetic mean, and one way analysis of variance (ANOVA) for multiple groups.

Table 1. Demographic data

\begin{tabular}{|c|c|c|c|c|}
\hline \multirow[b]{2}{*}{ Gender } & \multirow[b]{2}{*}{ Women } & \multicolumn{2}{|c|}{ number $\%$} & \multirow[t]{2}{*}{ Ort. \pm ss } \\
\hline & & 52 & 26,0 & \\
\hline & Men & 148 & 74,0 & \\
\hline \multirow[t]{4}{*}{ Your place of birth } & Bay & 16 & 8,0 & \\
\hline & Bel & 20 & 10,0 & \\
\hline & District & 40 & 20,0 & \\
\hline & Province & 124 & 62,0 & \\
\hline \multirow[t]{5}{*}{ Age } & $15-17$ & 4 & 2,0 & $4,060 \pm 0,905$ \\
\hline & $17-19$ & 8 & 4,0 & \\
\hline & $19-21$ & 28 & 14,0 & \\
\hline & $21-23$ & 92 & 46,0 & \\
\hline & $25-+$ & 68 & 34,0 & \\
\hline \multirow[t]{4}{*}{ Your Education } & Middle School & 4 & 2,0 & $2,536 \pm 1,225$ \\
\hline & High school & 36 & 18,0 & \\
\hline & University & 152 & 76,0 & \\
\hline & Graduate & 8 & 4,0 & \\
\hline \multirow[t]{5}{*}{ Your Income Level } & $250-500 \mathrm{TL}$ & 63 & 31,5 & $2,645 \pm 1,452$ \\
\hline & $600-1000 \mathrm{TL}$ & 41 & 20,5 & \\
\hline & $1100-1500 t \mathrm{tl}$ & 28 & 14,0 & \\
\hline & $1600-2000 \mathrm{TL}$ & 40 & 20,0 & \\
\hline & $2100+$ & 28 & 14,0 & \\
\hline \multirow[t]{6}{*}{ Age of Sport Start } & 05-07 age & 16 & 8,0 & $3,3400 \pm 1,30496$ \\
\hline & $08-10$ age & 41 & 20,5 & \\
\hline & $11-13$ age & 60 & 30,0 & \\
\hline & $14-16$ age & 25 & 12,5 & \\
\hline & 17 years and over & 58 & 29,0 & \\
\hline & Total & 200 & 100,0 & \\
\hline \multirow[t]{3}{*}{ Are you still in Club Activity? } & Yes & 67 & 33,5 & \\
\hline & No & 133 & 66,5 & \\
\hline & Total & 200 & 100,0 & \\
\hline
\end{tabular}

In the survey conducted on 200 sportsmen in sports facilities in Elazig, $52(26 \%)$ of the participants were female and $148(74 \%)$ of the participants were male.

Participants were born in $16(8 \%)$ in the village, $20(10 \%)$ in the district, $40(20 \%)$ in the district and $124(62 \%)$ in the province.

The average age of the participants is 4.06 (21-23) years. According to the educational status, 4 (2\%) are middle school, $36(18.0 \%)$ are high school, $152(76.0 \%)$ are university and $8(4 \%)$ The average education level is 2.53 (university).

According to the level of income, 4 (2\%) were aged 15-17, 8 (4\%) were aged 17-19, 28 (14\%) were 19-21, 92 (46.0\%) were 21-23 68 (34\%) of the participants were age 25 and over. It is seen that the age of starting sports is 3.34 (14-16) years. According to the current participation in club activities, 67 (33.5\%) were answered yes, and $133(66.5 \%)$ were given no response. 
Table 2. Expectation-Satisfaction analysis in terms of gender

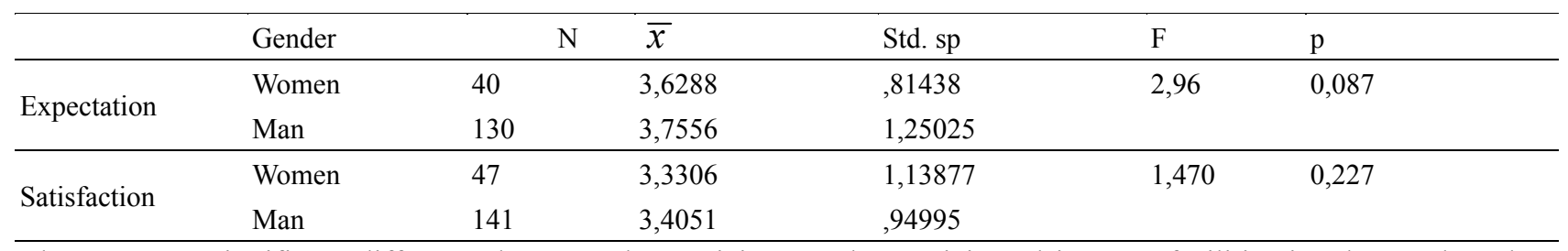

There was no significant difference between the participants who participated in sport facilities in Elazig when they examined gender of the expectation and satisfaction comparison questionnaire according to the t-test.

According to the expectation survey; Female Participants: $\bar{x} 3,62 \pm 0,814$, Male Participants: $\bar{x}$ 3,75 $\pm 1,250$ F: 2,96, p: 0,087

According to satisfaction survey; Female participants: $\bar{x}$ 3,33 $\pm 1,138$, Male participants: $3,40 \pm 0,949$ F: 1,470 , p: 0,227 . According to this;

There was no significant difference in expectation and satisfaction according to sex. But the expectation stems from the fact that the expectations are not met sufficiently because the expectations are higher than the average of satisfaction.

Table 3. Comparison of expectations and satisfaction in terms of birth place of participants participating in sports facilities operating in Elazig

\begin{tabular}{lllllll}
\hline & Place of birth & & \multicolumn{2}{c}{ The } & squares & \\
& & Sum of squares & df & mean & F & p \\
\hline Expectation & Between groups & 22,083 & 3 & 7,361 & 5,934 & \\
& In-group & 205,916 & 166 & 1,240 & & \\
& Total & 227,999 & 169 & &, 630 \\
Satisfaction & Between groups & 1,737 & 3 &, 579 &, 578 & \\
& In-group & 184,447 & 184 & 1,002 & & \\
& Total & 186,184 & 187 & & & \\
\hline
\end{tabular}

There was a meaningful difference in expectation and satisfaction according to place of birth. There was a significant difference between province and district, town and village in terms of expectation. Participants who were born were found to have higher expectations than those who were born in districts, towns and villages. There is no significant difference between provinces, provinces, towns and villages in terms of satisfaction. In other words, it has been seen that sports facilities operating in Elazig cannot meet expectations of all participants.

Table 4. Comparison of expectations and satisfaction in terms of age for participants participating in sports facilities operating in Elazıg

\begin{tabular}{lcccccc}
\hline & Place of birth & Sum of squares & df & $\begin{array}{c}\text { The squares } \\
\text { mean }\end{array}$ & F & p \\
\hline Expectation & Between groups & 53,352 & 4 & 13,338 & 12,601 &, 000 \\
& In-group & 174,647 & 165 & 1,058 & & \\
& Total & 227,999 & 169 & & & \\
\hline Satisfaction & Between groups & 15,987 & 4 & 3,997 & 4,297 &, 002 \\
& In-group & 170,198 & 183 &, 930 & & \\
& Total & 186,184 & 187 & & & \\
\hline
\end{tabular}

There was a meaningful difference between participants who participated in sports facilities operating in Elazig according to the Anova Turkey test according to the age-dependent place, in the expectation and satisfaction comparison questionnaire.

According to the expectation survey; Sum of squares between groups: 53,352, squares averages 13,338. Sum of squares in the group: 174,647, squares averages 1,058, F: 12,601, p: 0, 00

According to satisfaction survey; Sum of squares between groups: 15,987 , squares average of 3,997 . Sum of squares in the group: 170,198, squares averages of 0,930, F: 4,297, p: 0,002

There was a significant difference in expectation according to age dependent variable. There was a significant difference in age between expectations and age. It was seen that the expectation average of the participants aged 25 years and over was great. 
There was a significant difference in satisfaction with respect to age-dependent variables. There was a significant difference in age between expectations and age. Participants aged 25 years and over were found to have a low average of satisfaction.

Table 5. Expectation and satisfaction comparison of participants participating in sports facilities operating in Elazıg

\begin{tabular}{ccccccc}
\hline & Educational status & Sum of squares & df & $\begin{array}{c}\text { The squares } \\
\text { mean }\end{array}$ & F & p \\
\hline \multirow{3}{*}{ Expectation } & Between groups & 46,308 & 3 & 15,436 & 14,103 &, 000 \\
& In-group & 181,691 & 166 & 1,095 & & \\
& Total & 227,999 & 169 & & & \\
Satisfaction & Between groups & 6,661 & 3 & 2,220 & 2,276 & \\
& In-group & 179,523 & 184 &, 976 & & \\
& Total & 186,184 & 187 & & & \\
\hline
\end{tabular}

A significant difference was observed when participants in sports facilities operating in Elazıg were examined in terms of educational dependent variables according to the AnovaTukey test for the expectation and satisfaction comparison questionnaire.

According to the expectation survey; Sum of squares between groups: 46,308, squares averages 15,436 . Sum of squares in the group: 181,691, squares averages 1,095, F: 14,13, p: 0,00.

According to satisfaction survey; Sum of squares between groups: 6,661, squares averages 2,220. The sum of the squares in the group is 179,523 , the squares average is $0,976, \mathrm{~F}: 2,276, \mathrm{p}: 0,081$

There was a significant difference in expectation according to the education dependent variable. There was a significant difference in age between expectations and age. Bachelors - It has been seen that the expectation averages of the graduate participants are great.

According to education dependent variable, no significant difference was found in terms of satisfaction. All the training groups indicated that the expectations were not met, that is, they were not satisfied. It was seen that the average satisfaction level of the participants was low.

Table 6. Comparison of expectation and satisfaction in terms of income level of participants participating in sports facilities operating in Elazıg

\begin{tabular}{lcccccc}
\hline & Income rate & Sum of squares & df & $\begin{array}{c}\text { The squares } \\
\text { mean }\end{array}$ & F & p \\
\hline \multirow{3}{*}{ Expectation } & Between groups & 27,843 & 4 & 6,961 & 8,045 &, 000 \\
& In-group & 158,342 & 183 &, 865 & & \\
& Total & 186,184 & 187 & & & \\
\hline \multirow{3}{*}{ Satisfaction } & Between groups & 17,337 & 4 & 4,334 & 3,395 &, 011 \\
& In-group & 210,662 & 165 & 1,277 & & \\
& Total & 227,999 & 169 & & & \\
\hline
\end{tabular}

A significant difference was found when participants' participation in sports facilities in Elazıg was examined in terms of the level of income level dependent variables according to the AnovaTukey test.

According to the expectation survey; Sum of squares between groups: 27,843, squares averages 6,961 . The sum of squares within groups: 158.342 , squares average of $.865, \mathrm{~F}: 8.045, \mathrm{p}=0.00$

According to satisfaction survey; Sum of squares between groups: 17,337, squares average of 4,334. The sum of squares within groups: 210.662, squares average of 1.277, F: 3.39, p: 0.011

There was a significant difference in expectation according to income level dependent variable. 1100 - 1500TL participants with income levels 250-500TL according to income level seems to be higher than their expectations.

There was a significant difference in satisfaction with income level dependent variable. Participants with an income level of 2100 or more have a lower satisfaction level with participants with an income level of 1100-1500TL. 
Table 7. Comparison of expectations and satisfaction in terms of the age of participants in sports facilities in Elazig

\begin{tabular}{|c|c|c|c|c|c|c|}
\hline & $\begin{array}{l}\text { Age to start } \\
\text { sports }\end{array}$ & Sum of squares & df & $\begin{array}{c}\text { The squares } \\
\text { mean }\end{array}$ & $\mathrm{F}$ & $\mathrm{p}$ \\
\hline \multirow{3}{*}{ Expectation } & $\begin{array}{c}\text { Between } \\
\text { groups }\end{array}$ & 7,970 & 4 & 1,993 & 2,046 & ,090 \\
\hline & In-group & 178,214 & 183 & ,974 & & \\
\hline & Total & 186,184 & 187 & & & \\
\hline \multirow{3}{*}{ Satisfaction } & $\begin{array}{l}\text { Between } \\
\text { groups }\end{array}$ & 10,478 & 4 & 2,619 & 1,987 & ,099 \\
\hline & In-group & 217,521 & 165 & 1,318 & & \\
\hline & Total & 227,999 & 169 & & & \\
\hline
\end{tabular}

According to the AnovaTukey test, participants' participation in sports facilities in Elazıg was not significantly different from the age of onset of sport dependent change.

According to the expectation survey; Sum of squares between groups: 7,970, squares averages 1,993 . Sum of squares in the group: 178,214, squares average of 0,974, F: 2,046, p: 0,090

According to satisfaction survey; Sum of squares between groups: 10,447, squares averaging 2,619. The sum of the squares in the group is 217,521 , the squares average is $1,318, \mathrm{~F}$ is $1,987, \mathrm{p}$ is 0,099

There is no meaningful difference between expectation and satisfaction according to the age dependent on the start of sport. In other words, the age of the spore did not show a difference in expectations and satisfaction when using it for sports facilities.

Table 8. Comparison of expectation and satisfaction in terms of presence / absence of participants in sports facilities in Elazig

\begin{tabular}{ccccccc}
\hline & Are you still in Club Activity? & $\mathrm{N}$ & Ort & St.sap & $\mathrm{F}$ & $\mathrm{p}$ \\
\hline \multirow{2}{*}{ Expectation } & Women & 55 & 3,2259 & 1,15783 & 0,007 & 0,000 \\
& Man & 115 & 3,9649 & 1,08938 & & 0,155 \\
\multirow{2}{*}{ Satisfaction } & Women & 63 & 3,2405 & 1,01891 & 0,443 &, 98292 \\
& Man & 125 & 3,4600 & & \\
\hline
\end{tabular}

According to the t-test of the expectation and satisfaction comparison of participants who participated in sport facilities operating in Elazig, there was a meaningful difference when the current variable activity variable was examined.

According to the expectation survey; Yes Participants: $\bar{x} 3,22 \pm 1,157$, no: Participants: $\bar{x} 3,96 \pm 1,089$ F: 0,007, p: 0,000

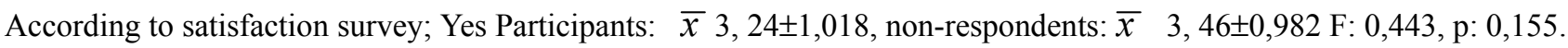
According to this

At present, there is a significant difference in the expectation of the dependent variable being in Club activity. It appears that participants who are not involved in club activities have higher expectations.

There is no significant difference in the satisfaction of the dependent variable from the club activity at present. In other words, all the participants were left below expectations of satisfaction.

\section{Discussion}

There was no significant difference in expectation and satisfaction according to sex. However, it can be thought that the expectation of expectations is higher than the average of satisfaction.

While Yelboga stated that the satisfaction of job satisfaction increases with age as he progressed in the job satisfaction survey in the finance sector, he found that there is no correlation between job satisfaction and demographic variables such as Gender, Age, Work experience, Education level in the work done by Öztürk . In this study, it was seen that there was no difference between the sex and the expectation, the expectation of the girl participants was higher, and all the group members were not satisfied according to the satisfaction level ( $p>0,05)$. (Yelboga, 2007)

Yaman and et. al. reported that the 12-17 age groups had more sports than the other age groups. In our study, it was seen in the age range of 11-16 and 17 years old. It has paralleled our work (Yaman, et.al.2007)

Nacar, In his work to determine the adequacy levels of sports facilities, participants reported that "the sports facilities 
were not adequate in terms of quality and quantity", "the inadequacy of the sports facilities did not give the political authorities the necessary boost to the sports facilities" (Nacar, 2011).

In a study conducted in the province of Elazıg, it has been stated that the physical characteristics of the sports facilities belonging to the Provincial Directorate of Youth and Sports in Elazig province are inadequate and do not comply with the definition of contemporary sports facility and cannot meet the existing needs (Nacar, 2011). Similarly, in a study conducted in Van, it has been stated that the reasons for not being able to use the sports facilities inadequately are the lack of suitable sports facilities and the physical capacity of the facilities (Karaca, 2002). In a study conducted in Nigde province, the sufficiency status of the facilities was asked with a question and it was determined that a large majority of the participants were insufficient due to the fact that the facility sufficiency could not respond to the needs and expectations, the facilities were inadequate and the spor- ans were away. The result of these investigations is parallel to our research.

Demiröz, It has been determined that the physical characteristics and management understanding of sports facilities belonging to GSIM in Kahramanmaras province cannot meet the needs and expectations of athletes and coaches and that different answers are given according to the survey items, sex and location. One thousand people said that 479 of them played sport partly. The facility and hall reported that this was the result of the inadequacy. In our study, sports facilities were not able to meet expectations in terms of gender, education, income levels according to participant's satisfaction survey (Demiroz, 2009).

There was a meaningful difference in expectation and satisfaction according to place of birth. There was a significant difference between province and district, village and village in terms of expectations. Participants who were born were found to have higher expectations than those who were born in districts, towns and villages.

There was no significant difference in expectation and satisfaction according to place of birth. There is no significant difference between the births in province, district, village and village in terms of satisfaction $(p>0,05)$. In other words, it has been seen that sports facilities operating in Elazig cannot meet expectations of all participants.

Demiroz, found that 18-24 (63,4\%), 25-31 (14,1\%), 32-38 (9,0\%), 39-45 (8,1\%), 46 years And over (5.4\%). This situation indicates that young people benefit from more sports facilities than other age groups. In our study, there was a significant difference between age groups in terms of expectation and satisfaction according to age dependent variable. It was observed that the expectation average of participants aged 25 years and older was higher than other age groups ( $\mathrm{p}$ $<0,05)$.

There was a meaningful difference in expectation and satisfaction according to place of birth. There was a significant difference between province and district, village and village in terms of expectations. Participants who were born were found to have higher expectations than those who were born in districts, towns and villages.

There was no significant difference in expectation and satisfaction according to place of birth. There is no significant difference between the births in province, district, village and village in terms of satisfaction $(p>0,05)$. In other words, it has been seen that sports facilities operating in Elazı $\breve{g}$ cannot meet expectations of all participants.

Demiroz, found that 18-24 (63,4\%), 25-31 (14,1\%), 32-38 (9,0\%), 39-45 (8,1\%), 46 years And over (5.4\%). This situation indicates that young people benefit from more sports facilities than other age groups. In our study, there was a significant difference between age groups in terms of expectation and satisfaction according to age dependent variable. It was observed that the expectation averages of participants aged 25 years and over were higher than other age groups $(\mathrm{p}<0,05)$.

There is more expectation of young adults than both adult and adult members about the expectations of the members who participate in the sports centers and their expectations about the quality of service and the perceptions of their perceptions. In our study it was seen that the expectations of participants aged 25 years and over were higher than the other age groups supports his research $(\mathrm{p}<0,05)$. (Yigit, 2013)

There was a significant difference in the Expectation according to the education dependent variable. Significant differences were observed between middle school and post-graduate participants. The attendance expectation of participants attending the graduate program was higher $(\mathrm{p}<0.05)$.

According to education dependent variable, there was no significant difference in satisfaction (p: 0,081). All training groups stated that their expectations were not met, ie they were not satisfied. Participants' satisfaction was found to be low.

Yigit in the work he has done; According to the education dependent variable, there was a significant difference in expectations. Bachelor - The bachelor supports the expectation of our work by expecting that the average expectation of the participants is great. 
There was a significant difference in expectation according to income level dependent variable. Participants with a income level of 1100-1500 TL have higher expectations than those with a income level of 250-500 TL. Keser, reported that the group with high income level had a high job satisfaction. In our study, it was seen that the group with income level of TL 1100-1500 had a higher level of expectation than the group with 250-500 TL income level. Again, in Keser's study, no significant difference was found when the satisfaction level of all income level groups was compared. It is parallel to our research. Although all the income level groups in our study differed from expectations, it was seen that the whole group was not satisfied enough in terms of satisfaction. There was a significant difference in satisfaction with income level dependent variable. Participants with an income level of 2100 or more have a lower level of satisfaction with participants with an income level of 1100-1500 TL. These results support my research on (Keser, 2005).

There is no significant difference in expectation according to the age dependent on the start of sport. In other words, the age of the spore did not show a difference in expectations and satisfaction when using it for sports facilities. In Öztürk's study, there was no significant difference between the age of onset of the spore and satisfaction in Sports centers. It supports our research (Öztürk, 2010).

At present, there is a significant difference in the expectation of the dependent variable being in Club activity. It appears that participants who are not involved in club activities have higher expectations.

There is no significant difference in the satisfaction of the dependent variable from the club activity at present. In other words, all the participants were left below expectations of satisfaction.

Yigit, showed that the difference between service quality points in comparison with the service quality subscale in terms of participation time is insignificant. In our study, Yigit, supports the result that there is no significant difference between the expectations of the new participants and the satisfaction of the participants in terms of the participation time (Yigit, 2013).

\section{Comparison of Sports and Social Facilities Survey Results}

12 of the 18 sports facilities participating in the survey and operating in the province of Elazig were examined. It was seen that 2 of these 12 sports facilities belonged to the public and 10 of them were private facilities for profit.

It has been observed that 11 of these facilities have common administrative offices.

All of these facilities have car parks and all of the facilities that work as carpets are sunny grass fields, 2 swimming pools, 4 facilities open sports facilities, 2 indoor fitness centers. One facility also has a training room. Nurseries were not found in these facilities.

Four of the 12 sports facilities we surveyed have a closed area of $250 \mathrm{~m} 2$. Eight of them were found to have a closed area of $1500 \mathrm{~m} 2.3$ of them were under $200 \mathrm{~m} 2,11$ of them were $200 \mathrm{~m} 2$ and above, and it was seen that they were open and closed. These are the private sector such as AA, LHS, and S23.

When energy usage capacities are examined, it is seen that the energy consumption of the six facilities is $5000 \mathrm{TL}$ or less per year and 8 of them have the energy consumption of 10.000 TL or more. These are the private sector such as AA, LHS, S23.

Two of the 4 swimming pool facilities in Elazıg province are 20 meters short and two 20 meters long swimming parks.

It did not have any quality standard document except for a publicly owned facility.

As of the usage capacities of the facilities reached 2200 people capacity and 7 facilities in 2014, 5 plants reached 7500 people capacity and above. These include the Yakup Kilic sports hall and the Youth Sports Directorate's swimming facilities belonging to the Public Youth Sports Directorate, and the SLHS, MHS and DHK businesses belonging to the private sector.

All of these facilities are staffed by the facility staff. There are no professional or private organization personnel.

There are 7 enterprises between 12000 - 40000TL according to the annual income situation of these facilities. There are 5 enterprises between 15000 and 150000 TL. These are the private sector such as AA, LHS, S23, the YakupKilic sports hall belonging to the Youth Sports Directorate and public facilities such as swimming facilities belonging to the Youth Sports Directorate.

The second plenary enterprises DKHS, LFS, LHS, S23 'from these plants are the second revenue generating enterprises. The second business is LFS and DHS business as the second income. These incomes are canteen and buffet income.

The most important enterprises in terms of operating expenses are S23, LHS, AA, FTHS, and SLHSAH.

Minimum wage is applied in all private companies. The most important enterprises for staff use are S23, LHS, AA, FTHS, and SLHS. The average price is between 1000-1200TL. There is not enough information on the number of personnel. 
The most important enterprises in terms of energy consumption are S23, LHS, AA, FTHS, and SLHS. Annual energy consumption is between $1000 \mathrm{TL}$ and $1200 \mathrm{TL}$ per month. The largest enterprise in terms of energy consumption is S23

The most important enterprises in terms of annual maintenance and repair costs are S23, LHS, AA, FTHS, SLHS. Maintenance and repair costs are between $200 \mathrm{TL}$ and $100 \mathrm{TL}$ per month. The largest enterprise in terms of energy consumption is LHS.

The most important enterprises in terms of paid annual tax expenditures are S23, LHS, AA, FTHS, and SLHS. Maintenance and repair costs are between $5000 \mathrm{TL}$ and $15000 \mathrm{TL}$ per year. The largest enterprise in terms of tax expenses is the AA carpet. As a result

In order for the working people to be able to play sports, sports halls must be opened by the business and every employee should benefit freely. Also, given the fact that fitness is providing fitness,

In order to spread the sport, people of all ages should be encouraged to play sports. Programs aiming at people aged between middle and upper ages should be prepared in order to broadcast the radio, television and written press in sports, writings about this subject should be written in newspapers and magazines, sports are given care full about the benefits to human health, It must be connected.

Findings obtained from the research can be said in the light that sports facilities in Elazig are not enough with respect to their physical and service qualities. The facilities should be brought to an adequate level with respect to quality and quantity. In Elazıg, sports facilities should be given priority in order to expand mass sports.

In general, sports are not activities that spend money in high amounts. For this, sport is not a privileged activity but a type of activity that needs to be widespread. However, it must be ensured that sufficient facilities are built and that the people can benefit from these facilities.

\section{Comparison of Sport and Social Facilities Survey Results}

In our comparison study of facilities, the largest enterprises in terms of Income, Business management, Energy, Tax and Personnel Expenditures are S23, LHS, and AA. None of these businesses have a certificate of standardization and are not managed by a professional operator.

\section{References}

Aktan, C. Ç. (1999). New Management Technique for Years 2000, Turkish Young Businessmen Association Publications: Istanbul.

Anatoliy, G. (2009). Improving of the efficiency through benchmarking: a case of Ukrainian breweries. Benchmarking: an international journal, 16(1), 70-87. https://doi.org/10.1108/14635770910936522

Argan, M., \& Katırc1, H. (2008). Sports Marketing (2nd Edition). Ankara: Nobel Publication Distribution.

Argüden, Y., \& Unanoglu, M. (2009). Benchmarking Research Development Consulting 1st Edition.

Barker, R., Saipe, R., Sutton, L., \& Tucker, L. (2003). BTEC National Sports Studies, by Heinemann.

Bektas, Ç. A. (2001). Tool in which service activities are organized according to Total Quality Management: Benchmarking Management, Standard Economic and Technical Review, Year 40, 477, 46-50.

Cristobal, S. R., Angel, R. M. L., \& Jose, G. C. (2003). Purchasing Function and Its Impact on Purchasing and Business Performance. Benchmarking: An International Journal, 10, 457.

Demiröz, M. V. (2009). Youth and Sports Provincial Directorate 'Evaluation of Physical Characteristics and Management Approach of Sports Facilities, Athletes and Coaches in terms of Needs and Expectations (Kahramanmaras Province)

Ertas, M. (2006). The Effectiveness and Qualities of Sports Institutions of Public Institutions and Organizations and Private Institutions in the Development of Life length Sports in Nigde Province, M.Sc. Thesis, Nigde University, Institute of Social Sciences, Nigde.

Fisek, K. (1980). Sport Management in Terms of Public Policy and Public Relations. Ankara: Ankara University Faculty of Sport Sciences. Publication.

Fisek, K. (2003). Sport Management in Terms of Public Policy and Public Relations: In the World and in Turkey.

Fisher, J. G. (1996). How to improve performance through benchmarking. Kogan Page.

Golgsmith, W. (2008).

http://www.sportscoachingbrain.com/why-bench-marking-is-a-waste-of-time-in-high-performance-sport/]

Güclü, M. (1998). Sports Facilities Operation: Ankara Special Yükselis College Sports Facilities. Pamukkale University 
Education Faculty Magazine, 4.

Hasan, K. G., \& Thomas, F. B. (2003). Management of Change in Today's Businesses: Methods and Applicability. Ataturk University Faculty of Economics and Administrative Sciences Journal, 14, 101.

IFA (Irish Football Association). (2006). "Official Website of the Irish Football Association" http://www.irishfa.com/grassroots/football-for-all-ffa-community-relations-strategy.

Jaffar, R., Mohamed, Z., \& Yasar, F. J. (2000). The Application of Graphical Techniques in Evaluating Benchmarking Journal of Economics and Administrative Sciences.

Karaca, S. (2002). Requests and Expectations of Sportsmen for the Use of Sports Facilities (Van Application), Graduate Thesis, Gazi University, Institute of Health Sciences, Ankara.

Kaya, B. (1997). An Efficiency Increasing Technique Approach: Benchmarking. Efficiency, 1: 59-78. Magazine; 24-25.

Keser, A. (2005). Relation of job satisfaction and life satisfaction, Journal of Labor and Society Economics and Law: 4.

Metin, Ç. (1980). Benchmarking, Book of Tüsîad-Kalder 4th National Quality Congress, Istanbul.1: 113.Number. 445.

Nacar. E. (2011). Determination of Proficiency Levels of Sport Facilities in Turkish Sports Education Ph.D. Thesis, F.U. Faculty of Health Sciences.

Nourayi, M. M. (2007). Profitability in Professional Sports and Benchmarking: The Case of NBA Franchises, Benchmarking: An International Journal, 2007(206), 252-271.

Özlem, N. Y. (2000). Examples of Bench marking are Business and Benchmarking Practices, Anadolu University Partners. Benchmarking an International Journal, 4, 304.

Öztürk, H. (2010). Determination of Customer Satisfaction Levels in Healthy Life and Sports Centers Marmara University. Department of Physical Education and Sports, Istanbul.

Peter, B. S., \& Diane, H. (2007). A model for Internal benchmarking, when and how?

Pınar, S. Ö. (1996). Benchmarking. Journal of Dokuz Eylül University Faculty of Economics and Administrative

Saraç, O. (2005). Benchmarking and Strategic Management. Court of Accounts Magazine, 56, 59.

Serarslan, M. Z. (2006). Sport Management and Case Analysis. Istanbul: Morpa Culture Publications.

Simsek, M. Ş, \& Celik, A. (2008). General Management. Konya: Education Academy Publications.

Sunay, H. (2005).Training of Sports Managers in Turkey and in the World. 46th International ICHPER-SD International Sports Science Congress Proceedings Istanbul; 121-130

Tanju, A. (1997). Performance and Benchmarking. Http: // www. Tanjuarpun.co. (28.03.2004)

Victory, A. (2002). Benchmarking. http://www.zaferagyar.cbj.net

Yaman, M., Ayan, S., \& Arslan, S. (2004). Analysis of Sports Facilities and Applied Policies for Dissemination of Sport TSA/240-255.

Yelboga, A. (2007). Analysis of the relationship between individual demographic variables and job satisfaction in the finance sector, Journal of Social Sciences, 4(2).

Yigit, S. (2013). Investigation of expectations and perceptions of the quality of service of the individuals participating insports centers Dumlupınar University Health Sciences Institute, Kütahya.

\section{Copyrights}

Copyright for this article is retained by the author(s), with first publication rights granted to the journal.

This is an open-access article distributed under the terms and conditions of the Creative Commons Attribution license which permits unrestricted use, distribution, and reproduction in any medium, provided the original work is properly cited. 